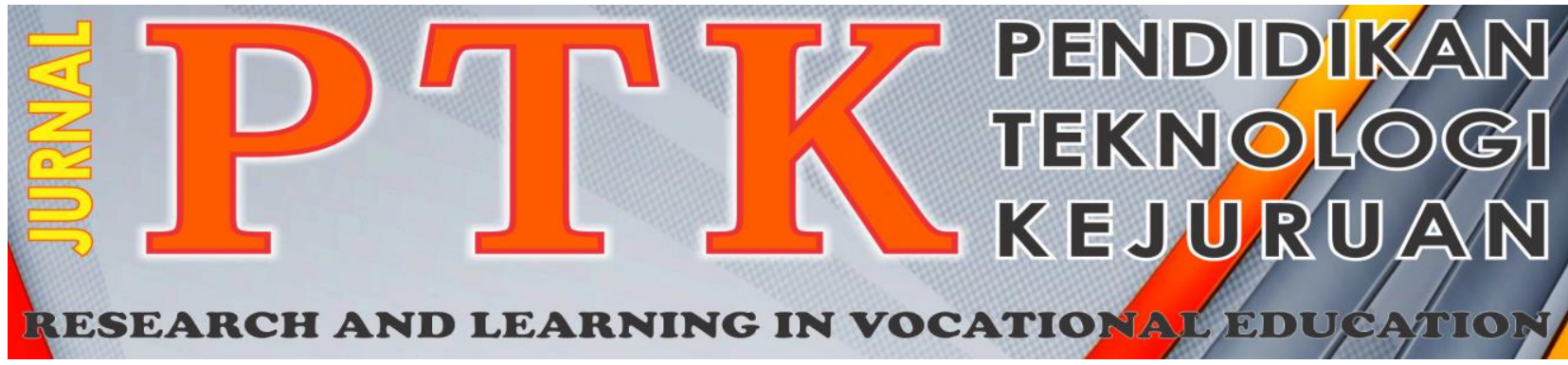

Vol. x, No. x bulan 201x

P-ISSN: 2621-3273

E-ISSN: 2621-1548

\title{
METODE SEISMIK DALAM PEMODELAN FISIS LETUSAN GUNUNG LUMPUR BLEDUG KUWU
}

\author{
Ahmad Fauzi Pohan ${ }^{1 *}$ dan Rusnoviandi ${ }^{1}$ \\ ${ }^{1}$ Teknik Pertambangan, STTIND Padang \\ *Corresponding author, e-mail: fauzipohan@ @ttind.ac.id
}

\begin{abstract}
Aktivitas gunung lumpur Bledug Kuwu di Jawa Tengah merupakan fenomena yang menarik dikaji menggunakan pemodelan fisis. Tujuan penelitian ini adalah mengetahui parameter dari medium gunung lumpur Bledug Kuwu. Adapun pemodelan fisis yang dilakukan dengan menggunakan media fisis akuarium berukuran $59 \times 59 \times 37,3 \mathrm{~cm}$ yang diisi material dari lumpur Bledug Kuwu. Sumber letusan dihasilkan dari tekanan kompresor yang dapat diatur kedalaman $(10.5,13$, dan $15.5 \mathrm{~cm})$ dan sudut $\left(30^{\circ}, 45^{\circ}\right.$ dan $\left.60^{\circ}\right)$ sumbernya. Sensor yang digunakan geophone komponen vertikal sebanyak 3 buah dengan durasi perekaman selama 5 dan 2,5 detik. Data diambil dengan frekuensi sampel 2 dan $4 \mathrm{kHz}$ untuk masing-masing durasi perekaman. Konfigurasi sumber dan geophone dibuat sesuai dengan pemodelan fisisnya. Pengukuran desnsitas lumpur menunjukkan angka sebesar $1200 \mathrm{~kg} / \mathrm{m}^{3}$. Berdasarkan hasil analisis seismogram model fisis diperoleh kecepatan perambatan gelombang-P pada medium lumpur Bledug Kuwu adalah sebesar 48,74 m/s,dan gelombang-S sebesar $28,14 \mathrm{~m} / \mathrm{s}$ dengan frekuensi dominan antara 20 sampai $25 \mathrm{~Hz}$.
\end{abstract}

Kata kunci: Metode Seismik, Model Fisis, Bledug Kuwu, Perambatan Seismik

Bledug Kuwu mud volcano activity in Central Java is an interesting phenomenon to be studied using both physical modeling. The objective of this study was to determine the physical parameters of the medium of Bledug Kuwu. The Physical model was an aquarium with a dimension of $59 \times 59 \times 37.3 \mathrm{~cm}$ filled with Bledug Kuwu's mud. The eruption source is generated by a compressor pressure that can be controled both the depth $(10.5,13$, and $15.5 \mathrm{~cm})$ and the angel of the source $\left(30^{\circ}, 45^{\circ}\right.$ and $\left.60^{\circ}\right)$. The resulting seismic signals were recorded by using 3 vertical component geophones for 10 and 5 seconds durations at a frequency of 2 and $4 \mathrm{kHz}$ respectivel, mud density 1200 $\mathrm{kg} / \mathrm{m}^{3}$. The physical modeling shows that the P-wave velocity of the Bledug Kuwu's medium is $48.7 \mathrm{~m} / \mathrm{s}$, S-wave velocity of Bledug Kuwu's is $28,14 \mathrm{~m} / \mathrm{s}$ with a dominant frequency of 20 to $25 \mathrm{~Hz}$.

Keywords：Seismic Method, Physical Modeling, Bledug Kuwu, Seismic Propagation

Copyright (C) 2018 JPTK. All rights reserved

\section{Pendahuluan}

Mud atau sedimentary volcanism adalah suatu proses keluarnya material di permukaan bumi secara kompleks yang merupakan lapisan sedimen yang terendapkan di bawah permukaan bumi yang dalam, seperti lumpur, bagian-bagian kecil atau blok-blok dari batuan, air garam dan gas yang di dominasi mengandung methana [1].

Gunung lumpur adalah fenomena geologi unik yang biasanya terjadi pada daerah yang terdapat aktivitas lempeng kompresi baik di darat maupun di laut. Ribuan dari fenomena gunung lumpur secara umum terdapat dibawah permukaan air [2].

Beberapa hal penting dari pembentukan dari gunung lumpur [3]; cepat atau lambatnya proses sedimentasi, tertutup dari lapisan sedimen yang tebal, adanya plastic stratum di bawah permukaan, tersedianya gas yang cukup dan tingginya potensial batuan hidrokarbon, formasi tekanan tinggi yang tidak normal, pada zona kompresi lempeng bumi, aktivitas seismik yang tinggi, dan adanya patahan.

Variasi bentuk kenampakan dari gunung lumpur tidak ada klasifikasi yang cocok untuk digunakan. 
Namun menurut Kopf[2] dalam menggambarkan skemanya, dibagi atas dua jenis yaitu kerucut (dome) dan datar (pie). Perbedaan antara dome dan pie terdapat pada sudut yang dibentuk antara pinggiran (flank) terhadap tanah.

Pulau Jawa memenuhi faktor-faktor terbentuknya gunung lumpur, sehingga memunculkan sederetan gunung lumpur yang terbentuk pada permukaannya. Beberapa hal yang menarik dari gunung lumpur yang muncul di Jawa Tengah hingga ke Jawa Timur diataranya Bledug Kuwu, yang memiliki aktivitas sangat kompleks dengan variasi erupsi dari ukuran besar hingga sangat kecil, yang terjadi pada beberapa saluran keluarnya material (conduit) [4].

Letusan gunung lumpur akan tetap terjadi jika memenuhi tiga komponen penting yaitu: sumber lumpur, jenis patahan, dan adanya kandungan gas didalam bumi. Patahan akan menjadi saluran yang dilalui oleh lumpur dan gas untuk keluar ke permukaan, bersamaan dengan pergerakan material pada saluran tersebut akan menghasilkan gelombang seismik yang merambat di medium. Fenomena naiknya material tersebut merupakan kajian menarik tersendiri dalam geofisika. Fenomena tersebut dapat dimodelkan secara fisis (pada skala laboratorium) [5-7].

\section{METODE}

Penelitian ini dilakukan di Laboratorium Teknik Geologi STTIND Padang.

\section{Pengukuran densitas lumpur Bledug Kuwu.}

Dilakukan dengan beberapa tahapan diantaranya:

a. Melakukan kalibrasi neraca analitik yang digunakan (gambar 1a).

b. Melakukan pengukuran massa dari gelas ukur (ukuran $250 \mathrm{ml}$ ) dalam keadaan kosong (gambar 1b).

c. Melakukan pengukuran massa dari gelas ukur dan sampel lumpur dan mencatat hasil pengukurannya (gambar 1c).

d. Mengulangi tahap a-c sebanyak 10 kali pengukuran

Densitas lumpur dapat dihitung dengan persamaan (1),

$$
\rho_{\text {lumpur }}=\frac{m_{\text {lumpur }}}{V_{\text {lumpur }}} .
$$

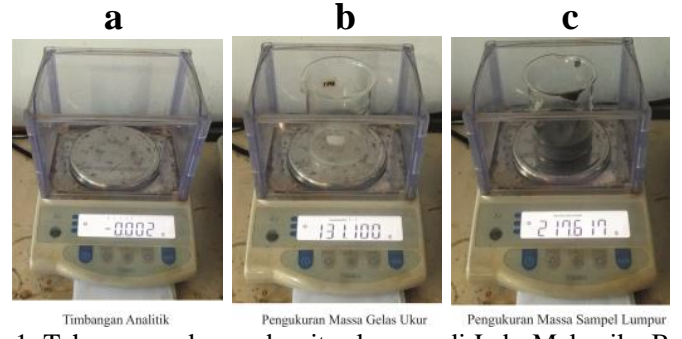

Gambar 1. Tahap pengukuran densitas lumpur di Lab. Mekanika Batuan STIIND Padang, (a) kalibrasi alat, (b) pengukuran gelas ukur, dan (c) pengukuran massa sampel lumpur.

\section{Perekaman seismogram model fisis.}

Adapun alat-alat yang digunakan dapat dilihat pada Tabel 1.

\begin{tabular}{ll}
\hline Alat-Alat & Jumlah \\
\hline Akuarim & 1 buah \\
Geophone & 3 buah \\
Styrofoam & 3 buah \\
Selang air & 1 buah \\
Penggaris & 1 buah \\
Kompresor & 1 buah \\
Busur derrajat & 1 buah \\
Data logger & 1 buah \\
Kamera digital & 1 buah \\
Komputer & 1 buah \\
\hline
\end{tabular}

\section{Teknik Pengumpulan data}

Penelitian ini akan melakukan pemodelan fisis dengan konfigurasi sensor (geophone) seperti pada Gambar 2, melakukan pengukuran dengan variasi kedalaman $\left(\theta=0^{\circ} /\right.$ tegak $)$ dari sumber letusan yaitu: 10.5, 13 dan $15.5 \mathrm{~cm}$. dan Gambar 3. melakukan pengukuran pada variasi sudut sumber yang membentuk sudut yaitu: $30^{\circ}, 45^{\circ}$, dan $60^{\circ}\left(\theta \neq 0^{\circ}\right)$.

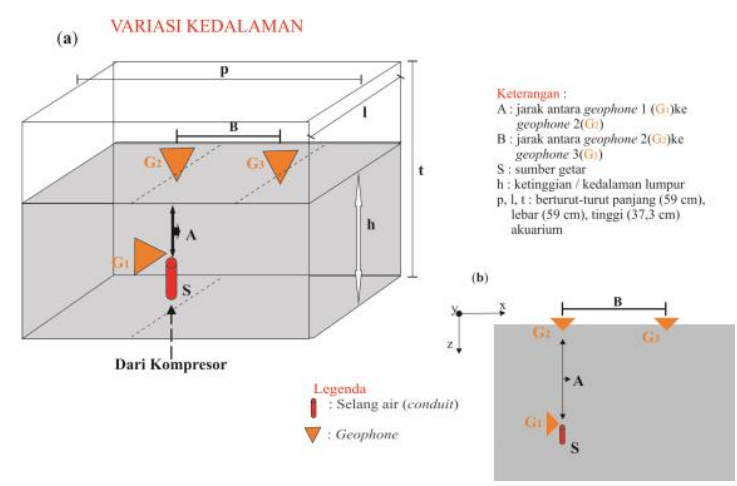


Gambar 2. (a) Kenampakan 3-D susunan geophone dan sumber getar dalam pengambilan data dengan memvariasikan kedalama sumber (A), (b) kenampakan secara 2-D.

Penempatan geophone 1 dekat dengan sumber bertujuan untuk merekam waktu awal letusan yang dilakukan (origin time). Dan peletakan geophone 2 dan 3 di permukaan lumpur bertujuan sebagai sensor rekaman seismik yang disebabkan oleh letusan lumpur. Susunan ketiga geophone ini dianggap sudah mewakili pengukuran yang sesungguhnya dilapangan.

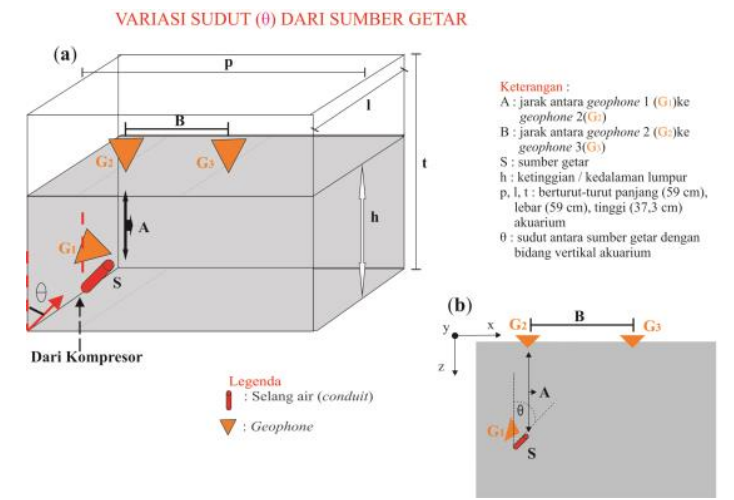

Gambar 3. (a) Kenampakan 3-D susunan geophone dan sumber getar dalam pengambilan data dengan memvariasikan sudut dari sumber getar $(\theta)$, (b) kenampakan secara 2-D

\section{Teknik Pengolahan Data}

Beberapa perangkat lunak dan perangkat keras yang digunakan antara lain: Komputer, CorelDRAW X7, Microsoft Excel, Matlab R2017a. Langkahlangkah pengolahan data yang dilakukan pada penelitian ini adalah sebagai berikut:

1. Mengubah data yang terekam dalam format 'WDQ' menjadi format 'txt'.

2. Memotong rekaman seismik (sinyal) yang mengandung event seismik.

3. Mengambil data gelombang pertama tiba dari event sinyal yang terekam di ketiga geophone.

4. Melakukan normalisasi terhadap sinyal yang dipilih.

5. Menghitung selisih/ beda waktu tiba gelombang pada tiap-tiap geophone yang merambat pada medium (lag time) dengan menggunakan crosscorrelation [8-9].

6. Menghitung kecepatan perambatan gelombang-P dengan Pers (2),

$v_{p}=\frac{\text { jarak antar geophone }}{\text { lag time }}$,

kemudian menghitung kecepatan perambatan gelombang-S dengan Persamaan (3),

$$
v_{s}=\frac{v_{p}}{\sqrt{3}} .
$$

Langkah 1-5 dilakukan secara berulang untuk semua data percobaan yang dilakukan (variasi kedalaman dan sudut dari sumber).

7. Melakukan FFT frekuensi dominan pada rekaman sinyal. Pengolahan data dimulai dengan melakukan langkah 1-2. Setelah langkah tersebut langsung melakukan FFT terhadap sinyal tersebut [9].

Langkah ini dilakukan secara berulang untuk semua hasil rekaman (variasi kedalaman dan sudut dari sumber).

\section{HASIL DAN PEMBAHASAN}

\section{Densitas dari lumpur Bledug Kuwu}

Adapun pengukuran densitas dari lumpur Bledug Kuwu dapat dilihat pada gambar 1. Pengukuran dilakukan secara berulang, hasil pengukuran ditunjukkan seperti pada table 2. Hasil tersebut menunjukkan bahwa nilai densitas lumpur Bledug Kuwu tersebut yaitu (Persamaan (1)):

$$
\begin{aligned}
& \rho_{\text {rata-rata }}=1227,2448 \mathrm{~kg} / \mathrm{m}^{3} \\
& \rho \approx 1200 \mathrm{~kg} / \mathrm{m}^{3}
\end{aligned}
$$

\section{Perekaman seismogram untuk variasi kedalaman.}

Seismogram perekaman model fisis yang dilakukan untuk variasi kedalaman (10.5 (biru), 13 (hijau), dan 15.5 (merah) $\mathrm{cm}$ ) diperlihatkan pada gambar 4, sedangkan untuk variasi sudut $\left(30^{\circ}\right.$ (biru), $45^{\circ}$ (hijau) dan $60^{\circ}$ (merah)) dapat dilihat pada gambar 5 .
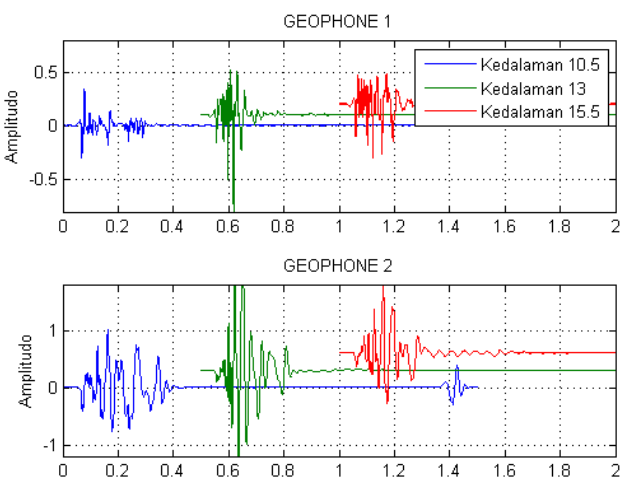

GEOPHONE 3

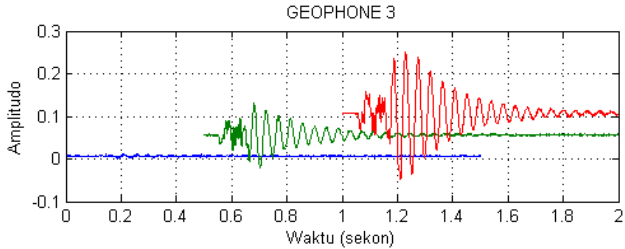


Gambar 4. Seismogram untuk variasi kedalaman.
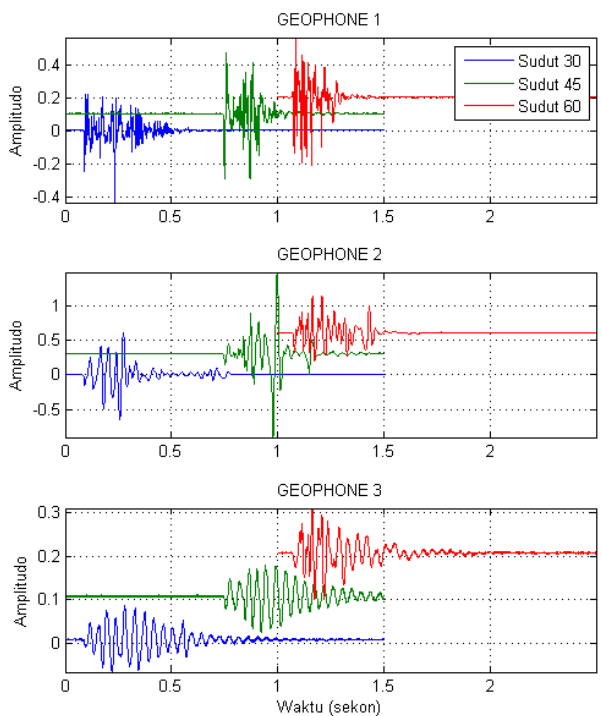

Gambar 5. Seismogram untuk variasi sudut.

\section{Hasil Pemotongan Sinyal}

Pemotongan gelombang pertama tiba dari event sinyal yang terekam di ketiga geophone (gambar 6). Untuk setiap variasi model fisis yang dilakukan. Kemudian setiap seismogram dilakukan korelasi silang (crosscorelation) (gambar 7) sehingga diperoleh lag time dari setiap geophone, dengan menggunakan Persamaan (2), maka diperoleh kecepatan perambatan gelombang-P pada tabel 3 dan 4.

Gambar 4. Seismogram untuk variasi kedalaman .
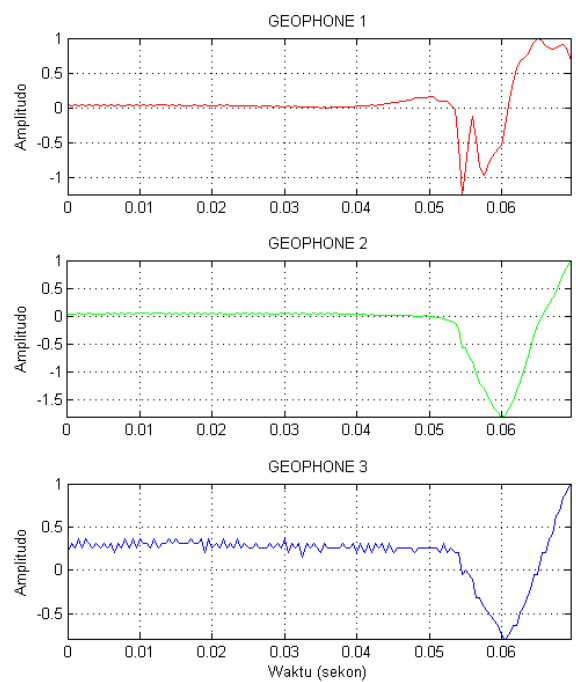

Gambar 6. Event gelombang seismik pertama.
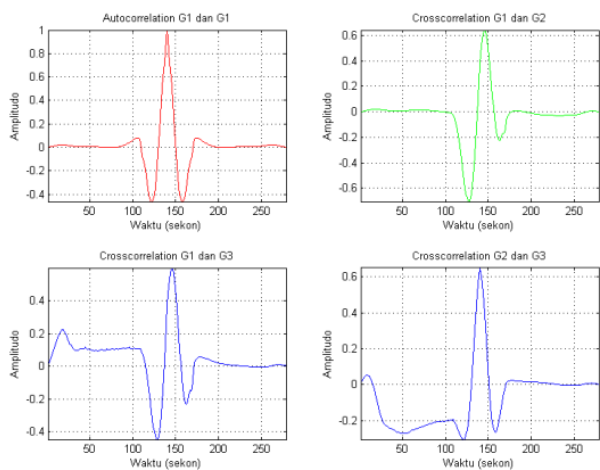

Gambar 7. Grafik hasil korelasi yang dilakukan antar geophone.

Dari tabel diperoleh kecepatan gelombang-P sebesar $48,74 \mathrm{~m} / \mathrm{s}$, maka kecepatan gelombang-S dapat dihitung dengan Persamaan (3).

$$
v_{s}=\frac{48,74 m / s}{\sqrt{3}}=28,14 \mathrm{~m} / \mathrm{s}
$$

\section{Hasil Fast Fourier Transfrom (FFT)}

Selain mencari perbedaan waku tiba gelombang yang direkam, juga dilakukan FFT. Dalam kawasan waktu gelombang yang terekam dengan menggunakan model fisis banyak mengandung fekuensi yang disebut dengan spektrum (gambar 8). Frekuensi dominan dapat memberikan informasi terhadap sinyal yang dihasilkan oleh sumber letupan buatan yang dilakukan, sehingga untuk mengetahui frekuensi dominan dari rekaman sinyal, dilakukan transformasi Fourier terhadap sinyal, dari hasil yang diperoleh menunjukkan bahwa spektrum gelombang berada pada kawasan frekuensi 20 sampai $25 \mathrm{~Hz}$ (Gambar 8).
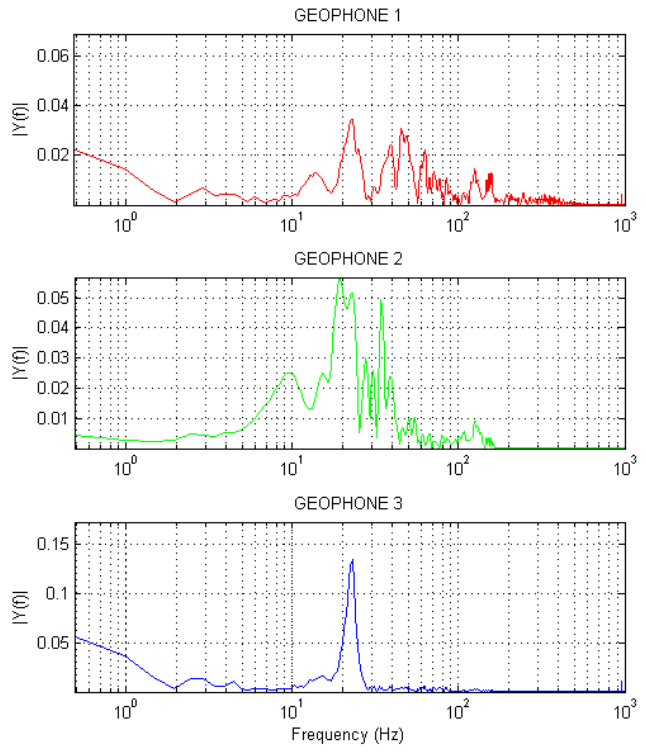

Gambar 8. Fast Fourier Transfrom dari rekaman seismik model fisis. 


\section{KESIMPULAN}

Berdasarkan hasil pengukuran massa dari sampel lumpur yang dilakuakan dan perekaman seismik dari model fisis, dapat disimpulkan bahwa:

1. Densitas lumpur Bledug Kuwu sebesar 1200 $\mathrm{kg} / \mathrm{m}^{3}$.

2. Kecepatann gelombang-P diperoleh sebesar $48,78 \mathrm{~m} / \mathrm{s}$ dan kecepatan gelombang-S sebesar $28,14 \mathrm{~m} / \mathrm{s}$.

3. Frekuensi sumber getaran yang dihasilkan pada medium lumpur Bledug Kuwu antara 20 sampai $25 \mathrm{~Hz}$

\section{UCAPAN TERIMA KASIH}

Terima kasih kepada DRPM Dikti yang telah mendanai penelitian ini. Dan dukungan dari Kampus Sekolah Tinggi Teknologi Industri (STTIND) Padang.

\section{DAftar Pustaka}

[1] Bonini, M., Mud volcanoes Indicators of stress orientation and tectonic control, Earth-Science Reviews, 115, Hal. 121-152, 2012.

[2] Kopf, A. J., Significance of Mud Volcanism, Reviews of Geophysics, 40, Hal. 1-52, 2002.

[3] Milkov, A. V., Worldwide Distribution of Submarine Mud Volcanoes and Associated Gas Hydrates, Marine Geology, 167, Hal. 29-42, 2000.

[4] Istadi, B. P., Pramono, G. H., Sumintadireja, P., and Alam, S., Modeling Study of Growth and Potensial Geohazard for LUSI Mud Volcano: East Java, Indonesia, Marine and Petroleum Geology, No.26, Hal. 1724-1739, 2009.

[5] Pohan, A. F., Wiwit S., dan Wahyudi., Pemodelan Model Fisis Letusan Gunung Lumpur Bledug Kuwu dan Pemodelan Numerik Untuk Mengetahui Kecepatan Perambatan Gelombang Seismiknya. Jurnal Fisika Indonesia Vol. 20 No. 2 p. 8-15, 2016.

[6] James, M. R., Lane, S. J., and Corder, S. B., Modelling The Rapid Near-Surface Expansion of Gas Slugs in Low-Viscosity Magmas, Fluid Motion in Volcanic Conduit a Source of Seismic and acoustic Signals, No.9, Vol.307, hal.147-167, 2008.

[7] Rust, A.C., Balmforth, N.J., and Mandre, S., 2008, The feasibility of generating low-frequency volcano seismicity by flow through a deformable channel, fluid motion in volcanic conduit a source of seismic and acoustic signals. Geophysics 307(9), 2008.

[8] Putranti, A. B., "Pemodelan Kecepatan Medium Bawah Permukaan Bledug Kuwu Dengan Metode Spatial Autocorrelation (SPAC)." Tesis, Fakultas MIPA: Universitas Gadja Mada, 2015.

[9] Brigham, E. O., The Fast Fourier Transform (FFT) and Its Applications, New Jersey, USA, Pretince Hall, 1988.

\section{Biodata Penulis}

Ahmad Fauzi Pohan, lahir di Rantau Prapat, 12 Januari 1990. Sarjana Pendidikan di Jurusan Pendidikan Fisika Unimed 2012. Tahun 2015 memperoleh gelar Master of Science di jurusan Fisika UGM dengan bidang konsentrasi Geofisika. Staf pengajar di program Studi Teknik Pertambangan STTIND Padang sejak tahun 2016sekarang.

Rusnoviandi, dilahirkan di Padang, 11 November 1981. Menyelesaikan S1 pada Bidang ilmu Teknik Pertambangan di Universitas Islam Bandung tahun 2004 dan pendidikan Pascasarjana (S2) Magister Manajemen di Universitas Padjadjaran tahun 2007. Dan Menjadi staf pengajar tetap Khusus di Program Studi Teknik Pertambangan STTIND Padang. 
Tabel 1. Hasil pengukuran densitas lumpur Bledug Kuwu.

\begin{tabular}{|c|c|c|c|c|c|c|}
\hline Percobaan & $\begin{array}{c}\text { Massa } \\
\text { gelas ukur } \\
(\mathrm{g})\end{array}$ & $\begin{array}{c}\text { Massa gelas } \\
\text { ukur dan } \\
\text { lumpur (g) }\end{array}$ & $\begin{array}{c}\text { Massa } \\
\text { lumpur }(\mathrm{g})\end{array}$ & Volume (ml) & Massa jenis $(\mathrm{g} / \mathrm{ml})$ & $\begin{array}{r}\text { Massa jenis } \\
\left(\mathrm{kg} / \mathrm{m}^{3}\right)\end{array}$ \\
\hline 1 & 131,1 & 217,617 & 87 & 50 & 1,73034 & 1730,34 \\
\hline 2 & 131,1 & 200,203 & 69 & 50 & 1,38206 & 1382,06 \\
\hline 3 & 131,1 & 196,302 & 65 & 50 & 1,30404 & 1304,04 \\
\hline 4 & 131,1 & 195,732 & 65 & 50 & 1,29264 & 1292,64 \\
\hline 5 & 131,1 & 183,892 & 53 & 50 & 1,05584 & 1055,84 \\
\hline 6 & 131,1 & 185,783 & 55 & 50 & 1,09366 & 1093,66 \\
\hline 7 & 131,1 & 188,77 & 58 & 50 & 1,1534 & 1153,4 \\
\hline 8 & 131,1 & 180,59 & 49 & 50 & 0,9898 & 989,8 \\
\hline 9 & 131,1 & 185,004 & 54 & 50 & 1,07808 & 1078,08 \\
\hline 10 & 131,1 & 190,731 & 60 & 50 & 1,19262 & 1192,62 \\
\hline & & & Rata-rata & & & 12272,48 \\
\hline
\end{tabular}

Tabel 3. Hasil pengujian kecepatan perambatan gelombang-P untuk variasi kedalaman sumber.

\begin{tabular}{cccccccr}
\hline \multirow{2}{*}{ Sudut $\left(^{\circ}\right)$} & Frekuensi & \multicolumn{6}{c}{ Kecepatan gelombang-P (m/s) } \\
\cline { 3 - 7 } & sampe (Hz) & 1 & 2 & 3 & 4 & 5 & Rata-rata \\
\hline \multirow{2}{*}{30} & 2000 & 41,2 & 30 & 55 & 27,5 & 55 & 41,8 \\
& 4000 & 44 & 47,1 & 38,8 & 55 & 50,8 & 47 \\
45 & 2000 & 50,5 & 39,3 & 44,2 & 35,4 & 44,2 & 42,8 \\
& 4000 & 50,5 & 39,3 & 44,2 & 35,4 & 44,2 & 42,8 \\
60 & 2000 & 64,2 & 77 & 77 & 55 & 96,2 & 74 \\
& 4000 & 70 & 70 & 55 & 70 & 59,2 & 64,8 \\
\hline
\end{tabular}

Tabel 4. Hasil pengujian kecepatan perambatan gelombang-P untuk variasi sudut sumber.

\begin{tabular}{cccccccr}
\hline \multirow{2}{*}{$\begin{array}{c}\text { Kedalaman } \\
(\mathrm{cm})\end{array}$} & $\begin{array}{c}\text { Frekuensi } \\
\text { sampel }(\mathrm{Hz})\end{array}$ & 1 & 2 & 3 & 4 & 5 & Rata-rata \\
\hline 10,5 & 2000 & 52,5 & 35 & 35 & 42 & 35 & 40 \\
& 4000 & 38,2 & 30 & 46,4 & 35 & 24,7 & 35 \\
13 & 2000 & 52 & 43,3 & 43,3 & 52 & 52 & 48,5 \\
& 4000 & 37,1 & 47,2 & 57,7 & 40 & 32,4 & 43 \\
15,5 & 2000 & 44,3 & 62 & 51,6 & 51,6 & 62 & 54 \\
& 4000 & 56,3 & 47,6 & 62 & 56,3 & 47,6 & 54 \\
\hline
\end{tabular}

